\title{
“This English writing thing”: Students' perceptions of their writing experiences at an English-medium university
}

\author{
Bojana Petri \\ Department of English Applied Linguistics \\ Eötvös Loránd University, Budapest
}

Received: 10 October 2006 / Accepted: 13 November 2006

ISSN: $1697-7467$

\begin{abstract}
This article explores five students' perceptions of their writing experiences at an English-medium post-graduate university in a non-English speaking country as compared to writing in their home country universities in their native languages. Three types of differences are found to be relevant: language and rhetorical differences, disciplinary differences, and differences in educational systems (such as the number of assignments required, the focus of writing instruction, and feedback practices). The analysis shows that some of these differences are unexpected for the students and require a period of adjustment during their transition to an English-medium university. The article concludes by discussing the implications of the findings for English for academic purposes.
\end{abstract}

Key words: student writing at university, students' perceptions, English-medium university, English for academic purposes

\section{INTRODUCTION}

Due to increasing numbers of students studying in English-medium universities worldwide, English for Academic Purposes, and English academic writing in particular, has become a dynamic field of research. However, as Leki (1995: 11) notes, research has tended to focus on teaching "rather than on L2 students and their academic literacy experiences", which has led to a neglect of students' voices (Leki, 2001), a view shared by many scholars (e.g., Johns, 1997; Hyland, 2000; Braine, 2002). Yet, exploring the student perspective can reveal important issues, such as discrepancies between students' writing needs in content courses and writing tasks in writing courses (Leki \& Carson, 1997).

When exploring students' perspectives, it is important to place them in the context of the increasing variety of English-medium universities and the social and political environments in which they operate. Most research into student perspectives on their literacy experiences has been conducted with international students in US universities (Leki, 1995; Leki \& Carson, 1994, 1997; Tardy, 2004, 2005; see also Braine, 2002 for a review), where such students make a distinct group in need of special support. Fewer studies have investigated student 
perspectives in English-medium programmes in non-English speaking countries, such as, for example, Israel (Ferenz, 2005), where students share the first language but study in English, or with students for whom English is an additional language, as in South Africa (Thesen, 1997). Still less is known about students' experiences in international English-medium universities in non-English speaking countries, where both students and faculty come from various first language backgrounds and where English is used as a lingua franca (ELF) (Seidlhofer, 2005). The differences in the role of English in different English-medium universities and the countries where they are located (as second (ESL), foreign (EFL), additional language (EAL), or lingua franca (ELF)) may have an important impact on students' positions vis-à-vis the university and the larger society, which are then likely to influence their experiences and attitudes towards studying in it as well as their academic achievement.

In this exploratory study, I examine the writing experiences of students studying at an English-medium post-graduate university in a non-English speaking country in Central Europe. These students have previously obtained a first degree in non-English-medium institutions in their native countries in the Central and Eastern European region. For such students, meeting the writing requirements of English-medium universities may be particularly demanding since they come from educational systems in which writing has traditionally played a less important role, especially in assessment procedures (for further information on the role of writing in educational systems in Eastern Europe, see Petri, 2005). As students are likely to bring with them assumptions about academic literacies formed on the basis of their previous experiences (Johns, 1997), it is of interest to explore how they percieve the differences between the two systems. Based on interviews with five students, I explore the types of differences students note between writing in the two universities, which is followed by a discussion of the implications for English for Academic Purposes at English-medium universities and for further research in this area.

\section{EXPLORING STUDENTS' PERCEPTIONS IN CONTEXT}

The participants in this study are five master's students at an English-medium postgraduate university in Central Europe. They differ in terms of national and language backgrounds (two are from Poland, one each from Czech Republic, Serbia, and Kazakhstan) as well as previous and current areas of study. What they have in common is that they graduated from universities in their native countries before the start of higher education reforms that followed some time after the fall of communism.

The English-medium University where the study was conducted was founded by an American philanthropist and is based on the American model of education, markedly different from universities in the participants' countries in many respects. Its student body and faculty come from a variety of countries. In the area of writing, the major differences include the obligatory introductory academic writing course, a first such course for many of the students, and the writing centre, an educational unit providing students with advice on their written assignments.

The study was conducted at the end of the first semester, when students were writing their final term papers, and had already gained some experience of studying in the new context. They had also completed an introductory academic writing course and had had 
individual consultations on their assignments with writing instructors at the writing centre. A semi-structured interview was conducted with each participant. Interview themes included students' writing histories in their native language and other languages they are able to write in, including English, writing instruction they received in any language, the role of writing in their previous and present studies, the difficulties they encounter and their opinions of the differences between writing academically in English and their native language. The interviews were transcribed and analysed following Holliday (2002). The students' names were replaced by pseudonyms.

\section{WRITING IN A DIFFERENT LINGUISTIC, CULTURAL AND EDUCATIONAL SYSTEM}

When talking about their writing experiences at the English-medium University, participants referred to various types of difference in relation to their previous university. As Agne aka put it, "everything is different":

Agne aka: My first meeting with this English writing thing was this year and it was horrible [laughter]

Interviewer: Why?

Agne aka: Because it was like ... first of all the structure of the sentence is completely different and the structure of the essay is different, everything is different.

Three types of difference were identified: language and rhetorical differences, differences between the educational systems, and disciplinary differences. In what follows I discuss each type of perceived differences.

\subsection{Language and rhetorical differences}

The students emphasise the impact of language and rhetorical differences between English and their native languages on the fluency and speed of their writing in English. Differences in their linguistic proficiency in the two languages are especially constraining in the area of vocabulary.

Maria and Ana describe the impact of the limited English vocabulary on the writing process: Maria keeps interrupting writing "to look for synonyms because [her] vocabulary is poor", and Ana is "on a constant search of trying to find the English ways of saying things in Serbian". Agne aka points to a particularly important issue in academic writing when she talks about her struggle to express appropriate writer stance when quoting other authors:

My problem is with [phrases] like

'the author claims', 'argues', 'it seems to be', in Polish I don't have so many

problems because my vocabulary is bigger (Agne aka)

The lack of easily accessible language resources does not only make writing in English a slower process but also hinders the students' ability to communicate their writing goals. Maribal, Maria and Ana describe the difficulty of expressing their writing intentions in English and the inability to feel the nuances of meanings their writing conveys: 
Sometimes I cannot express my opinion, I use some words but it is not suitable for the sentence and it looks funny, but in Russian it's easy. (Maribal)

Sometimes I just don't feel that the word, for example, this example of 'tricky' I didn't know it was too colloquial. (Maria)

Sometimes I fall into the trap of just translating Serbian constructions into English, and for me they are clear but I am not aware of the fact that for someone they are not clear. (Ana)

The students are aware that because their vocabulary choices may communicate different meanings than the ones they intended, they may sound "funny", "colloquial" and "not clear". More than simply a language problem, the limited vocabulary resources restrict the students' ability to be in control of the writing persona their writing in English projects. To illustrate this with Maria's statement above, although she did not intend to use colloquial words, her use of such words may be interpreted as a lack of knowledge about the basic features of academic writing in general rather than as a result of her lack of language resources in English.

At the same time, students also note that it would be difficult to write about their areas of study in their native languages due to the fact that specialist terminology comes from English and often develops at a faster pace than scholarship in smaller languages, since developing suitable equivalents or ways to absorb new terminology in appropriate ways is a time consuming process.

Students also note differences in the writing patterns in English and in their native languages, i.e., rhetorically different ways of writing valued in different academic communities. Maria, Ange aka and Ana refer to differences relating to cohesion, clarity, concision, and focus in writing. All three regard writing in English as more cohesive, concise ('shorter' as Ana describes it) and characterised by having a narrower focus than writing in their languages:

In English I have to always think that the paper must be cohesive and must be clear, and in Polish, when I write, my thoughts can be a bit vague. And in English I have to be strict, I have to focus strictly on the subject, on the topic (Maria)

[in English] you have to have a really clear vision. I think that Polish academic writing is more ... let's say unclear (Agne aka)

In English, you have this and this amount of words and it's more condensed, it can't stay broad and vague (Ana)

In Polish you can write in the introduction something general. Even doesn't have to be strictly connected to the paper, to the main body. And in English it's impossible (Maria).

These excerpts also illustrate the participants' efforts to comply with what they perceive is the convention of writing in English. Both Maria and Agne aka talk about having to do something when writing in English, be it keep "think[ing] that the paper must be cohesive" (Maria), or having to have a "clear vision". Similarly, Ana and Maria talk about what cannot be done in English: "it can't stay broad and vague" (Ana), "in English it's impossible" (Maria). In contrast to this language of obligation and impossibility used to describe writing in English, the participants describe writing in their native languages using the modals of possibility: for example, when writing in her native language, Maria feels that her "thoughts can be a bit vague". 
The interviews also show that the participants see these differences as part of some larger differences and not simply a result of different levels of linguistic ability in English and their native languages. In the following excerpt, Ange aka talks about different types of rhetoric valued in different academic cultures:

In Polish it's better when you write longer structure, longer sentences, it's better seen, if you are an academic you have to be clever, write long sentences [laughs] or sophisticated vocabulary, and sometimes when I read English it's easier. (Agne aka)

Ana similarly refers to the differences in the ways of writing preferred in different academic cultures and, since she is trilingual, provides an interesting comparison of writing in Japanese, Serbian and English. She compares the rhetorical patterns of the three languages in terms of what she calls "length". Thus the Japanese way of writing is "the longest one":

In Japanese, you have to write long, and to use metaphors, but at the same time give background, just about anything that you put in the paper. The more you write, it's the better. (Ana)

Serbian is seen as "somewhere in the middle" since it imposes some structural restrictions but "you can put all sorts of things in the appendix", while English is at the other end of this continuum as it is "more condensed" and "you have to look at your sentence and take out everything that's not necessary".

Maria goes even a step further, regarding the differences as not only rhetorical but also cognitive, reflecting different patterns of thought:

If I read academic papers, academic articles, in Polish and English, it's really, you can feel the difference in thinking. (Maria)

These observations are accompanied by value judgments. Maria and Ana express contrasting attitudes towards "English writing". Maria considers it better suited to academic writing than her native language:

And I think that in the case of academic writing, the more clear, more proper way is the English one... I am sure that if I start writing in Polish now - academic papers or something - that I changed my style because this... experience here of English style of writing. (Maria)

In contrast, Ana does not see one pattern superior to another, but feels "enriched" by knowing how to write using and combining the rhetorical patterns of different languages:

I will be able to transfer some of it into my Serbian writing in order to be able to make it more efficient and also keep some characteristics of Serbian or Japanese writing that I like.... So I am enriched with this pattern of efficient but somewhat unreliable [simplified] academic structure. (Ana) 
As can be seen, they both state that "the English pattern" will influence their writing in their native languages, a point deserving further research.

\subsection{Differences between the educational systems}

In addition to language and rhetoric, the students relate their writing experiences to the differences between the educational systems their previous and present university are part of. Numerous issues emerged, of which I discuss three: the number of assignments, writing instruction and feedback practices.

\subsubsection{Number of assignments}

Although the participants come from different countries, a common pattern is that at the universities in their home countries there is much less emphasis on written assessment:

You get the grade by final oral exams, there is no tradition of writing papers. There were like 3 or 4 papers during 5 years (Maria)

It was mostly oral exams but final thesis was written (Maribal)

It [writing in his previous studies] wasn't like one assignment per week and it wasn't such a huge work (Franti aek)

Hence coming to the university where assessment is mostly based on written assignments and finding out that they will be required to write about six papers per semester may provoke strong anxiety. Agne aka talks about how she felt at the beginning of her studies at this university:

I thought it would be impossible to write six papers [...] Two months ago, I would wake up at night and feel a pain in my stomach thinking "all these papers in two months" (Agne aka)

Maria, who had spent a final year of her undergraduate studies as an exchange student in the Netherlands, went through a similar experience when entering a new system:

But there were a lot of papers in the Netherlands, that's what surprised me, there I had to write 3 or 4 papers per semester, and I thought "oh my God" [laughs] and that was like a real challenge because I didn't have any knowledge about how I should do that, there was no special course like here, so that was a challenge, I had to rely on myself.

These excerpts show that some of the differences in educational contexts, such as the number of assignments, not only require different skills from the students but also have an emotional effect if the students do not feel confident they can fulfill the requirements. 


\subsubsection{Writing instruction}

In the excerpt above, Maria makes an important point that she was not only unprepared for the demands of a different educational system but also had no place to turn to for writing support. Ana also mentions the lack of writing instruction in her previous education:

There was no focus on writing, and we never, until I came to this graduate school, I never had any sort of instruction about how to write except from the supervisors themselves, and in that case, as much as they could, if they have time or they see it to be necessary (Ana)

Later in the interview, Ana reiterates this point, this time also reflecting on the way the whole system functions:

It's just very typical in Belgrade nobody tells you about it [how to structure the paper] and if you can't come to that conclusion yourself, then you are lost. But it's not such a big deal because you are not, you know, you write two semester papers, and they just throw away the technical stuff, and look for the line of your thought and that's it in a way (Ana)

In this excerpt, Ana relates the existence of writing instruction to the importance of writing in the educational context. This leads her to conclude that the lack of writing instruction is not a drawback in her previous university since in that educational system writing is not a crucial skill for academic achievement. Therefore, in that system, when students are required to write, what is valued is not the skill ("the technical stuff") but the substance ("the line of your thought").

Agne aka, in contrast, refers to writing instruction in her native language, but stresses the differences in focus:

Agne aka: It was in high school and it was in Polish writing.

Interviewer: What was it like?

Agne aka: Well, there was no need to have structure as in English, so the clear thesis, the main parts of the essay... It was just like "Tell me what you think about it"

This comment points to a discrepancy between writing instruction in secondary education and the types of writing required at university, noted in many countries (for an overview, see Foster \& Russell, 1990). A similar transition takes place when students move from undergraduate to postgraduate levels of study. When this transition is coupled with transition to a new university context in a different country, where writing may play a different role and is valued in a different way, students may have difficulty understanding writing demands. Even when course syllabi contain descriptions of writing requirements, students may not be familiar with the concepts or terms used. In such cases, students may continue to rely on practices inappropriate in the new context and may need a period of trial and error. 


\subsubsection{Feedback practices}

Another perceived difference between the educational systems relates to the professors' feedback to student writing. There is a difference in the amount of feedback, due to, as Maria points out, different ratios between students and professors:

There was always support from your advisor, but when your advisor had like 20 students per year, it's very difficult for him to help you much (Maria)

This comment explains her following point, which stresses the lack of detailed feedback in the previous studies:

When I wrote my MA thesis I had no comments that I had to change something, style or structure (Maria)

Ana similarly points to the lack of detailed feedback in her previous studies, which she contrasts with focused and detailed feedback at this university:

[At the university in my country] the idea is important, what I say is important [...] the only thing that sometimes they ask you to correct is referencing [...] Here [at the English-language university] they take apart each sentence, and that's ok in a way, but there are just two different emphases. (Ana)

Ana relates the differences in feedback practices to larger differences in the educational contexts, which, in her view, are characterised by "just two different emphases". She develops this idea further:

Here [at this university] you need to have consultations on a regular basis, while there, Belgrade or I guess most of Eastern Europe, or sometimes even in England, that's what I've heard, you are left with your topic, on your own, to do your own stuff, after half a year you come for a consultation and then you present what you've done and then they give you some sort of a feedback [stresses the word], but here you get more like instructions, not so much feedback. Like, yes, it's labelled 'feedback' but it's like instructions, it's much more firm." (Ana)

By contrasting 'feedback' and 'instructions', Ana points to important differences between the two models of university education. One allows student independence "to do your own stuff", while the other rests on supervision or even control over student progress in writing and research. She makes a distinction between European universities, which she believes encourage independent work, and the American model, which she sees as relying on "tight supervision":

I never understood why Americans call the university a school, where I would say I am going to the university [...] Now that I think about it, I realise university is like a kindergarten, you are under tight supervision (Ana). 
These accounts of differences in educational contexts show the students' awareness of the fact that educational practices shape the ways writing is valued, taught, commented on, and graded. It is clear that these are not language based differences. As Ana says:

It's a different system, it's not about whether it's in English or not. I'd probably have the same type of problems in Serbian if somebody could really sit down and deal with my writing in Serbian. (Ana)

Finally, it is important to note the emotional overtones in these accounts, such as Maria's "surprise" at the number of assignments to be written or Agne aka 's "pain in the stomach" caused by anxiety, or Ana's obvious dislike of feedback that is more like "instructions". These expressions signal that writing practices in the new university may put students in uncomfortable, face-threatening, situations to which different students respond in different ways. This, however, may remain an invisible part of the learning process if it is not addressed in the writing course.

\subsection{Disciplinary differences}

Franti aek, whose previous degree was in metallurgical engineering and who is now studying towards an MA in Environmental Science and Policy, compares his writing experiences in the previous and the present universities in terms of the differences between the disciplines:

Interviewer: How important was writing in your previous studies?

Franti aek: Writing wasn't so important because the study was based mostly on a kind of reports, technical data, but not such kind of thing like essays, and particularly, it was in Czech, so it's a little bit different for me to write in English in this particular area - Czech and my technical background.

He contrasts two different types of texts required in different types of study: reports, technical data, technical background in studying metallurgical engineering, as opposed to essays in studying environmental science and policy. Later in the interview Franti aek refers to differences in types of assignments as the largest difference again:

It [writing in his previous studies] was based on other principles, it was mainly based, as I said before, on data, this kind of things, it wasn't concerned about grammar, about structure of sentences, sometimes wasn't even complete sentences, it was some kind of notes, some kind of reports, with points. (Franti aek)

Research has shown that disciplines differ in terms of writing conventions and the types of genres employed, especially when it comes to 'hard' and 'soft' sciences (Hyland, 2000). Consequently, training in these disciplines emphasizes different aspects of writing. The reason why Franti aek is the only student to mention these differences may be the fact that he is the only one in the group with a 'hard' science background moving to a different discipline. Disciplinary differences may be relevant not only when students move from one discipline to another but also when they embark on interdisciplinary studies, which is a growing trend in higher education. 


\section{Discussion}

As this study is based on interviews with a small number of students, it provides only a glimpse into what strikes students as different when they begin writing academically at an English-medium university, as compared to writing in academic contexts in their own countries in their native languages. The findings nevertheless show that differences between languages, writing patterns, educational systems and disciplines are strongly felt by these and possibly other students in similar contexts and may present them with difficulties and obstacles in their university study at English-medium universities. One of the implications is that English language and writing instruction should be available to students at English-medium universities both in the form of introductory courses and support units, such as writing centres, where students can seek advice when needed.

Many questions for further research arise: to what extent do the perceived differences cause difficulties in learning? What views are formed as a result of writing experiences in different educational systems and how do they affect learning through English? How does studying in an English-medium university affect writing for academic purposes in the native language? Such questions are likely to become more important with increasing numbers of English-medium universities worldwide. A theme that is likely to become particularly important is the impact of the status of English in the wider context in which the English-medium university is located on students' learning experiences and outcomes and, in relation to that, the differing roles of EAP instruction in contexts where English is the main language of wider communication, a second, or a foreign language. Although the goal of EAP instruction is to prepare students for studying in English regardless of the context, different issues may be relevant in designing EAP instruction in different environments. Where English is used as a lingua franca, for example, students will be communicating with other speakers of English as a lingua franca more often than with native speakers of English, which may have important implications for determining syllabus priorities. Also, the issue of transfer of the writing conventions of students' first languages into English writing and vice versa, mentioned by the participants in this study, may be more significant in non-English speaking countries.

At the same time, comparisons of findings from studies of student perspectives on their writing experiences in different contexts may open up further questions for research. For example, the participants in Tardy's (2004) study, graduate students from various Asian countries studying in a US university, perceive writing in English as more concise, clear, and less ambiguous than in their native languages, which is almost identical to the perceptions of the participants in this study, coming from Slavic language backgrounds. Why do students from different linguistic backgrounds perceive writing in English in similar ways? Does this have to do with linguistic features of English, different writing conventions as studied by contrastive rhetoric (see Connor, 1996), or English writing instruction? As more data is gathered on student perceptions of their academic literacies, new light may be shed on these issues.

Student perspectives on their literacy experiences can also provide a necessary reality check for EAP pedagogy. Regardless of the context, it is important to take into account academic literacy practices the students bring with them from previous institutional contexts, especially at post-graduate levels of study. One way of achieving this is by creating a space in the EAP curriculum for reflection and discussion of issues related to students' transition to an English-medium university. 


\section{Bibliography}

Braine, G. (2002). "Academic literacy and the nonnative graduate student", Journal of English for Academic Purposes, 1/1: 59-68.

Connor, U. (1996). Contrastive Rhetoric. Cambridge: Cambridge University Press.

Ferenz, O. (2005). "EFL writers' social networks: Impact on advanced academic literacy development", Journal of English for Academic Purposes, 4/4: 339-351.

Foster, D. \& Russell, D. R. (eds.) (2002). Writing and Learning in Cross-National Perspective. Transitions from Secondary to Higher Education. Mahwah, NJ: Lawrence Erlbaum.

Holliday, A. (2002). Doing and Writing Qualitative Research. London: Sage.

Hyland, K. (2000). Disciplinary Discourse. Social Interactions in Academic Writing. Harlowe: Longman.

Johns, A. M. (1997). Text, Role and Context. Developing Academic Literacies. Cambridge: Cambridge University Press.

Leki, I. (1995). "Coping strategies of ESL students in writing tasks across the curriculum", TESOL Quarterly, 29/2: 235-260.

Leki, I. (2001). "Hearing voices: L2 students' experiences in L2 writing courses", in T. Silva \& P. K. Matsuda (eds.), On Second Language Writing. Mahwah, NJ: Lawrence Erlbaum.

Leki, I. \&. Carson, J.G. (1994). "Students' perceptions of EAP writing instruction and writing needs across the disciplines", in TESOL Quarterly, 28/1: 81-102.

Leki, I. \& Carson. J.G. (1997). “'Completely different worlds': EAP and the writing experiences of ESL students in university courses", TESOL Quarterly, 31,1: 39-70.

Petri, B. (2005). "Contrastive rhetoric in the writing classroom: A case study", in English for Specific Purposes, 24, 2: 213-228.

Seidlhofer, B. (2005). "English as a lingua franca", ELT Journal, 59/4: 339-341.

Tardy, C. (2004). "The role of English in scientific communication: lingua franca or Tyrannosaurus rex?", in Journal of English for Academic Purposes, 3/3: 247-269.

Tardy, C. (2005). “'It's like a story': Rhetorical knowledge development in advanced academic literacy", in Journal of English for Academic Purposes, 4/4: 325-338.

Thesen, L. (1997). "Voices, discourse, and transition: In search of new categories in EAP", in TESOL Quarterly, 31/3: 543-560. 